\title{
Clinical Effects and Toxicokinetic Evaluation Following Massive Topiramate Ingestion
}

\author{
Michael J. Lynch • Anthony F. Pizon • \\ Mohamed G. Siam • Matthew D. Krasowski
}

Published online: 8 April 2010

(C) American College of Medical Toxicology 2010

\begin{abstract}
Topiramate is used to treat a variety of neurologic and psychiatric diseases due to its benign safety profile. Data regarding the toxicity and toxicokinetics of topiramate in acute overdose are limited. A case of massive, acute ingestion resulting in the highest reported topiramate level is presented, including toxicokinetic evaluation. A 37year-old woman presented with coma unresponsive to naloxone following topiramate ingestion. She had normal vital signs without respiratory depression. She was intubated for airway protection, given $3.5 \mathrm{mg}$ lorazepam IV for facial and neck muscle twitching, and transferred to our facility. No additional sedation was required for $18 \mathrm{~h}$ on the ventilator. Following mental status improvement, the patient was extubated. Confusion, dysarthria, and imbalance resolved over the next 2 days. Nonanion gap metabolic acidosis persisted for 3 days. Peak serum topiramate level was $356.6 \mu \mathrm{g} / \mathrm{ml}$ (reference range, 5$20 \mu \mathrm{g} / \mathrm{ml}$ ). Massive topiramate ingestion led to prolonged coma with normal vital signs and nonanion gap metabolic acidosis. Coma of this severity has not been previously reported. Serum half-life, which has not been studied after
\end{abstract}

M. J. Lynch $(\bowtie) \cdot$ A. F. Pizon

Division of Medical Toxicology, Department of Emergency

Medicine, University of Pittsburgh Medical Center,

Pittsburgh, PA, USA

e-mail: lyncmj@upmc.edu

M. D. Krasowski

Department of Pathology,

University of Pittsburgh Medical Center,

Pittsburgh, PA, USA

M. G. Siam

Department of Forensic Medicine and Toxicology,

Zagazig University,

Zagazig, Egypt overdose, was $16 \mathrm{~h}$. Despite the large ingestion and significant presenting symptoms, the patient recovered fully with supportive intensive care alone. Massive acute topiramate ingestion may lead to nonanion gap metabolic acidosis and prolonged coma which resolves with intensive supportive care. Toxicokinetic data following large, suicidal ingestion of topiramate were similar to previously published pharmacokinetic information.

Keywords Topiramate $\cdot$ Coma $\cdot$ Toxicokinetics . Metabolic acidosis

\section{Background}

Topiramate is a sulfamate-substituted monosaccharide anticonvulsant used in the treatment of various seizure disorders and as a mood stabilizer. Pharmacologic activities include reduction in voltage-gated sodium currents, increase in the frequency of GABA receptor binding, and antagonism of kainate binding at the kainate/AMPA site of the glutamate receptor [1]. Topiramate is also an inhibitor of the CA-II and CA-IV isoenzymes of carbonic anhydrase [1]. Pharmacokinetic studies have shown a plasma elimination half-life of $18-24 \mathrm{~h}$ [2]. Less than $20 \%$ of the drug is metabolized, with the inactive metabolites 10 hydroxytopiramate, 2,3-O-desisopropylidene topiramate, 9-hydroxytopiramate, and 4,5-O-desisopropylidene topiramate identified [3].

In therapeutic doses, topiramate is generally well tolerated [4]. However, the data regarding topiramate toxicity in humans continues to be limited to few case reports and one poison center review. The most commonly reported symptoms in a large poison center review included neurologic abnormalities such as tremor, sedation, ataxia, 
nystagmus, and slurred speech [5]. Coma was only reported in one out of 567 cases reported to poison centers [5]. Metabolic acidosis related to its carbonic anhydrase activity is a well-known adverse effect of topiramate, but is not associated with significant morbidity [6-9]. Pediatric ingestions have yielded similar toxicity as well as hallucinations in young children $[8,10]$. There is one published report of a fatality attributed to topiramate ingestion. Postmortem central blood topiramate concentration was $170 \mu \mathrm{g} / \mathrm{ml}$ with levels also measured in the liver, stomach, and vitreous fluid [11]. Case reports of survival following topiramate toxicity demonstrated levels of 9.4 and $10.5 \mu \mathrm{g} /$ $\mathrm{ml}[8,10]$. The reference range for topiramate levels in the laboratory at our institution is $5-20 \mu \mathrm{g} / \mathrm{ml}$.

Experience with topiramate toxicity is limited, but would indicate that serious adverse effects may occur but fatalities are rare. Toxicokinetic data following massive overdose has not been reported. We report a case of the largest acute ingestion of topiramate based on a Medline search of topiramate toxicity in the English literature, including toxicokinetic analysis.

\section{Case Report}

A 37-year-old woman with a history of bipolar disorder treated with topiramate and diazepam presented to an outlying emergency department via Emergency Medical Service when her husband was unable to wake her. In addition to her prescribed medications, the only medication she had access to was ibuprofen. He had last seen her awake and acting normally roughly $12 \mathrm{~h}$ earlier. In the emergency department, she was witnessed to have facial twitching and clonic movements of her head which were interpreted as seizure activity. These movements resolved with $3.5 \mathrm{mg}$ of intravenous lorazepam. The patient remained unresponsive following naloxone administration and was intubated for airway protection without need for further sedation or paralytic administration. An arterial blood gas drawn at that time revealed a metabolic acidosis with $\mathrm{pH} 7.26, \mathrm{pCO}_{2} 41 \mathrm{mmHg}$, and $\mathrm{pO}_{2} 320 \mathrm{mmHg}$. Serum chemistry evaluation included bicarbonate of $21 \mathrm{mEq} / \mathrm{L}$ with an anion gap of 16 . Urine $\mathrm{pH}$ was 8.0. Serum salicylate, acetaminophen, and ethanol levels were undetectable. The remainder of her laboratory evaluation was unremarkable. Computed tomography of the brain without contrast did not reveal acute pathology. As this was felt to be related to a toxic ingestion, the patient was transferred to a regional toxicology treatment center.

Examination revealed no evidence of distress on the ventilator without sedation or paralysis. Her vital signs were temperature $36.8^{\circ} \mathrm{C}$, pulse $68 \mathrm{bpm}$, respirations $14-16$ breaths per minute with the ventilator set to $14-16$ breaths per minute, and blood pressure $110 / 58 \mathrm{mmHg}$. Intact brainstem reflexes and brisk extremity reflexes without clonus were evident on neurologic examination. Her pupils were $3 \mathrm{~mm}$ and normally reactive bilaterally. The patient responded with localization to painful stimuli in bilateral upper and lower extremities. With the exception of chronic bilateral upper and lower extremity skin excoriations, the remainder of her physical examination was unremarkable.

Arterial blood gas results were $\mathrm{pH} 7.31, \mathrm{pCO}_{2} 36 \mathrm{mmHg}$, and $\mathrm{pO}_{2} 374 \mathrm{mmHg}$. Basic metabolic panel included the following: sodium $141 \mathrm{mEq} / \mathrm{L}$, potassium $3.4 \mathrm{mEq} / \mathrm{L}$, chloride $111 \mathrm{mEq} / \mathrm{L}$, bicarbonate $16 \mathrm{mEq} / \mathrm{L}, \mathrm{BUN} 10 \mathrm{mg} /$ $\mathrm{dl}$, creatinine $1.0 \mathrm{mg} / \mathrm{dl}$, and an anion gap of 14 . Her arterial lactate was $1.0 \mathrm{mmol} / \mathrm{L}$. Liver function tests, complete blood count, and coagulation studies were all within normal limits. Urinalysis revealed a urine $\mathrm{pH}$ of 9.0 and was otherwise unremarkable. Urine comprehensive drug screen performed using gas chromatography and mass spectrometry (GC/MS) [12] showed large spikes corresponding to topiramate (retention time, $19.9 \mathrm{~min}$ ) and ibuprofen. A smaller peak (retention time, $20.9 \mathrm{~min}$ ) was identified by its fragmentation spectrum in the GC/MS library as 10hydroxytopiramate. Medications the patient was known to take or have access to were detectable by GC/MS. Serum topiramate level was measured to be $356.6 \mu \mathrm{g} / \mathrm{ml}$ (reference range, $5-20 \mu \mathrm{g} / \mathrm{ml}$ ) using a specific immunoassay for topiramate (Polymedco Clinical Diagnostics, Cortland Manor, NY). Topiramate levels are available and routinely performed at our institution. The serum sample required dilution with drug-free serum in order to bring the concentration within the linear range for the immunoassay. The linear range of the topiramate assay in our laboratory extends to $75 \mu \mathrm{g} / \mathrm{ml}$. We assayed the sample using fivefold, tenfold, and 20-fold dilutions. These gave values of $366 \mu \mathrm{g} /$ $\mathrm{ml}$ (using fivefold dilution), $354 \mu \mathrm{g} / \mathrm{ml}$ (using tenfold dilution), and $350 \mu \mathrm{g} / \mathrm{ml}$ (using 20-fold dilution). The mean of these three values was $356.6 \mu \mathrm{g} / \mathrm{ml}$. The coefficient of variation for these values is $2.3 \%$, showing little variation introduced by the dilutions. A serum ibuprofen level measured by high-performance liquid chromatography [13] from blood drawn concurrently with the topiramate level was $12.0 \mu \mathrm{g} / \mathrm{ml}$ (reference range, $5-50 \mu \mathrm{g} / \mathrm{ml}$ ).

The patient slowly woke over the following $12 \mathrm{~h}$. She was extubated on hospital day 2 without evidence of acute pulmonary disease. Prior to extubation, $18 \mathrm{~h}$ following admission, repeat arterial blood gas was $\mathrm{pH} 7.30, \mathrm{pCO}_{2}$ $30 \mathrm{mmHg}$, and $\mathrm{pO}_{2} 179 \mathrm{mmHg}$. Serum chemistries at that time revealed measured bicarbonate of $14 \mathrm{mEq} / \mathrm{L}$ with an anion gap of 10. Her speech continued to be slurred for the next $24 \mathrm{~h}$ with ataxia, nystagmus, and mild persistent somnolence. This gradually improved by the third day of hospitalization when she was ambulatory, conversant, and tolerating a normal diet. Her nonanion gap metabolic 
acidosis persisted. Serum chemistry evaluation on day 3 showed no significant change in nonanion gap metabolic acidosis with a measured bicarbonate of $13 \mathrm{mEq} / \mathrm{L}$ and anion gap of 11 .

Serial serum topiramate levels were obtained in order to determine elimination toxicokinetics. The initial level of $356.6 \mu \mathrm{g} / \mathrm{ml}$ is far greater than previously reported levels, more than double a postmortem level associated with death [11]. We measured four levels. The first, at 1615 on hospital day 1 , was $356.6 \mu \mathrm{g} / \mathrm{ml}$. The next level performed at 0955 the following day was $173.6 \mu \mathrm{g} / \mathrm{ml}$. The next two levels were 61.2 and $44.0 \mu \mathrm{g} / \mathrm{ml}$ on the third day of hospitalization at 0841 and 1555 , respectively (see Fig. 1). These levels, plotted on a semi-log graph versus time, demonstrate first-order kinetics with a calculated serum half-life of $16 \mathrm{~h}$. The patient was unable to remember the time or dose of ingestion. She had been on topiramate for the previous year and was currently prescribed $100 \mathrm{mg}$ by mouth twice a day. She had no previous drug levels available for review. The patient did report that she was not fully compliant with the dosing.

The patient was transferred to an inpatient psychiatric facility on the third day of admission due to the suicidal intent of her ingestion. At the time of transfer, her symptoms had significantly improved despite persistent acidosis and elevated topiramate levels.

\section{Discussion}

Topiramate is a commonly used anticonvulsant and mood stabilizer. Though its use at therapeutic levels has a benign safety profile, we have relatively little experience with this drug in the setting of intentional overdose. This case documents the clinical course and elimination kinetics in a patient following a massive ingestion of topiramate.

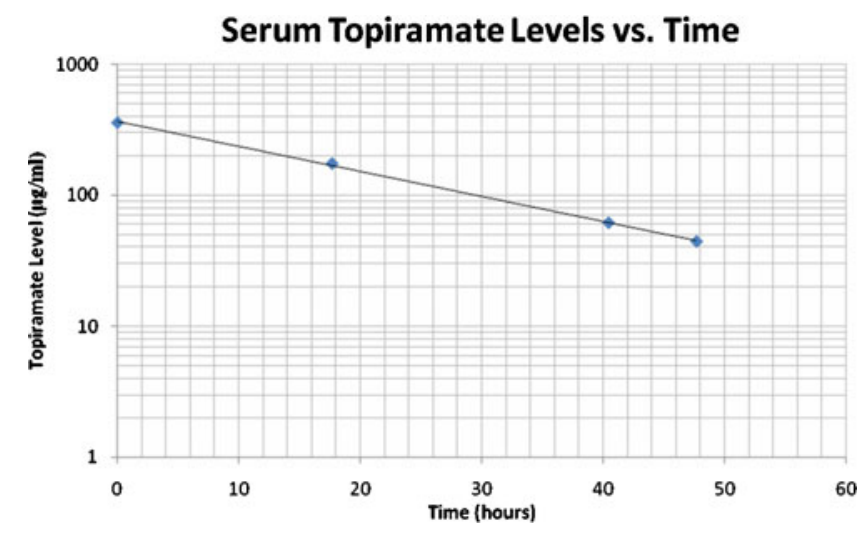

Fig. 1 Serum topiramate levels versus time. The time at which the topiramate level was drawn is time $=0 \mathrm{~h}$ as the exact time of ingestion was unknown. The linear distribution of topiramate levels on a semi$\log$ plot indicate first-order elimination kinetics
It is unclear whether this patient's movements represented true seizure activity versus myoclonic jerks prior to our evaluation. She had no evidence of seizure activity during our observation. Previous reports of seizure-like activity following topiramate ingestion have included two patients providing a history of very large topiramate doses $(>400 \mathrm{mg} / \mathrm{kg}$ ) and one case of a patient naïve to the drug [6, 7]. However, qualitative urine GC/MS evaluation and serum levels confirming topiramate exposure were not performed. Animal studies have proposed an early proconvulsant mechanism of topiramate followed by delayed anticonvulsant activity which may explain reported seizure activity [14].

This patient also demonstrated coma. She tolerated endotracheal intubation and mechanical ventilation for approximately $18 \mathrm{~h}$ following initial presentation without additional sedation after the $3.5 \mathrm{mg}$ of intravenous lorazepam given at the outlying emergency department. Coma of this depth and duration has not been reported. Altered level of consciousness without coma as well as unusual behavior have most commonly been described [5, $8,10]$. One case series of six patients described stuporous encephalopathy in patients taking therapeutic doses of topiramate in combination with valproic acid or other anticonvulsants, but not with topiramate alone [15]. Despite her comatose state, the patient did not exhibit significant respiratory depression or vital sign abnormalities. With supportive intensive care, the patient recovered quickly.

The patient also displayed nonanion gap metabolic acidosis with alkaline urine consistent with topiramate's known carbonic anhydrase activity. Multiple case reports and case series have demonstrated nonanion gap metabolic acidosis without clinical significance [6-9]. Despite her significantly depressed serum bicarbonate concentrations, the patient never developed severe acidemia. Following transfer from the emergency department, her arterial blood $\mathrm{pH}$ was never below 7.3 and she did not require intravenous bicarbonate infusion.

Finally, toxicokinetic evaluation of topiramate's elimination following the largest documented ingestion does not reveal significant alteration in the half-life. In this patient, the elimination half-life of $16 \mathrm{~h}$ is slightly shorter than what has been previously reported following therapeutic dosing $(18-25 \mathrm{~h})$, but not significantly so [2, 16]. Further evaluation of absorption and distribution could not be performed as the original dose remained unknown.

\section{Conclusion}

We present this case of suicidal topiramate overdose in order to add to the limited existing data, particularly in patients with large, intentional ingestions. Due to its 
increasing use as a mood stabilizer in psychiatric patients, it is likely that we will continue to be confronted with these ingestions. Close observation and supportive care would be our recommendations based on this patient and review of the literature regarding this drug.

Acknowledgements M.D.K. is supported by a physician-scientist career development grant K08-GM074238 from the National Institutes of Health (NIH). The authors also thank Darla Lower (University of Pittsburgh Medical Center, Toxicology and Therapeutic Drug Monitoring Laboratory) for technical assistance with GC/MS analysis.

\section{References}

1. Markind JE (1998) Topiramate: a new antiepileptic drug. Am J Health Syst Pharm 55(6):554-562

2. Bialer M (1993) Comparative pharmacokinetics of the newer antiepileptic drugs. Clin Pharmacokinet 24:441-452

3. Britzi M, Soback S, Isoherranen N, Levy RH, Perucca E, Doose DR, Maryanoff BE, Bialer M (2003) Analysis of topiramate and its metabolites in plasma and urine of healthy subjects and patients with epilepsy by use of a novel liquid chromatography-mass spectrometry assay. Ther Drug Monit 25(3):314-322

4. Patsolos PN, Sander JW (1994) Newer antiepileptic drugs: towards an improved risk-benefit ratio. Drug Saf 11:37-67

5. Lofton LA, Klein-Schwartz W (2005) Evaluation of toxicity of topiramate exposures reported to poison centers. Human Exp Toxicol 24(11):591-595
6. Fakhoury T, Murray L, Seger D, McLean M, Abou-Khalil B (2002) Topiramate overdose: clinical and laboratory features. Epilepsy Behav 3:185-189

7. Anand JS, Chodorowsk Z, Wisniewski M (2007) Seizures induced by topiramate overdose. Clin Toxicol 45(2):197

8. Traub SJ, Howland MA, Hoffman RS, Nelson LS (2003) Acute topiramate toxicity. J Toxicol Clin Toxicol 41(7):987990

9. Philippi H, Boor R, Reitter B (2002) Topiramate and metabolic acidosis in infants and toddlers. Epilepsia 43:744747

10. Lin G, Lawrence R (2006) Pediatric case report of topiramate toxicity. Clin Toxicol 44(1):67-69

11. Langman LJ, Kaliciak HA, Boone SA (2003) Fatal acute topiramate toxicity. J Anal Toxicol 27(5):323-324

12. Pizon AF, Schwartz AR, Shum LM, Rittenberger JC, Lower DR, Giannoutsos S, Virji MA, Krasowski MD (2008) Toxicology laboratory analysis and human exposure to p-chloroaniline. Clin Toxicol 14:1-5

13. Minkel PE, Hoppel CL (1988) Determination of ibuprofen in human plasma by high-performance liquid chromatography. J Chromatogr 428:388-394

14. McDonald P, McLean M, Thomas R (2001) Topiramate has acute proconvulsant and delayed anticonvulsant effects on cultured central neurons and a mouse seizure model. Neurology 56(Suppl): A332-A333

15. Latour P, Biraben A, Polard E, Bentue-Ferrer D, Beauplet A, Tribut O, Allain H (2004) Drug induced encephalopathy in six epileptic patients: topiramate? valproate? or both? Hum Psychopharmacol 19(3):193-203

16. Bialer M, Doose DR, Murthy B, Curtin C, Wang SS, Twyman RE, Schwabe S (2004) Pharmacokinetic interactions of topiramate. Clin Pharmacokinet 43(12):763-780 